\title{
COMPREENSÃO DO ORIENTADOR PEDAGÓGICO SOBRE AS DIFICULDADES DOS PROFESSORES PARA O ENSINO DA LÍNGUA MATERNA
}

\author{
Lais Agnes da Silva, Renata Portela Rinaldi \\ Universidade Estadual Paulista - UNESP, Departamento de Educação, Curso de Pedagogia, Presidente Prudente, SP. E- \\ mail: lais.aunesp@gmail.com. Agência de fomento: CNPq
}

\begin{abstract}
RESUMO
A escola atual apresenta diversos desafios e sérios problemas. O fracasso escolar dos estudantes quanto a aquisição da língua materna, sem dúvidas, pode ser considerado um desses grandes desafios. Este trabalho tem como objetivo apresentar as principais dificuldades que os professores das escolas do município de Presidente Prudente enfrentam para o ensino de língua materna, na perspectiva do Orientador Pedagógico (OP). Trata-se de uma pesquisa qualitativa e o instrumento utilizado para coleta de dados foi o questionário. Diversas dificuldades apareceram nas falas, tais como: falta de apoio da família, dificuldade de aprendizagem, salas numerosas, defasagem no processo de aquisição da escrita etc. Concluímos que para que o OP tenha a capacidade de dar assistência ao professor, é preciso que ele tenha uma ampla bagagem de conhecimentos específicos e pedagógicos, sobre a língua materna, bem como sobre as mais diversas dificuldades que seus pares docentes enfrentam.
\end{abstract}

Palavras-Chave: Orientador pedagógico, Língua Materna, Alfabetização, Letramento.

\section{UNDERSTANDING OF THE PEDAGOGICAL FORMES ON THE DIFFICULTIES OF TEACHERS FOR THE TEACHING OF THE MATERNAL LANGUAGE}

\begin{abstract}
The present school presents several challenges and serious problems. The failure of students to acquire their mother tongue, without doubt, can be considered one of these great challenges. This paper aims to present the main difficulties that the teachers of the schools of the municipality of Presidente Prudente face for the teaching of mother tongue, from the perspective of the Pedagogical Cordinator. It is a qualitative research and the instrument used for data collection was the questionnaire. Several difficulties appeared in the speeches, such as: lack of support from the family, difficulty in learning, numerous rooms, lag in the process of acquiring writing. We conclude that for the PB to be able to provide assistance to the teacher, he must have a wide range of specific and pedagogical knowledge about his mother tongue as well as the many difficulties his / her faculty members face.
\end{abstract}

Keywords: Pedagogical Cordinator, Mother tongue, Literacy. 


\section{INTRODUÇÃO}

A escola atual apresenta diversos desafios e sérios problemas, como: os diferentes fatores da exclusão social, os elevados índices de repetência e evasão, dificuldade para o ensino da língua materna, entre outros. O fracasso escolar dos estudantes quanto a aquisição da língua materna, sem dúvidas, pode ser considerado um dos grandes desafios que a escola tende a enfrentar nos dias atuais. Pois, como cita Parisotto (2014), saber ler e escrever de modo proficiente em língua materna é primordial para o desenvolvimento de toda pessoa que está inserida em uma cultura letrada.

Ainda, de acordo com a autora, observa-se que o professor dos anos iniciais do ensino fundamental não possui apoio teórico-metodológico que norteie a sua prática pedagógica e, consequentemente, reproduz "[...] conteúdos programáticos desajustados da realidade do aluno, priorizando o estudo da metalinguagem, ou seja, o estudo da nomenclatura gramatical, deixando de propiciar aos seus alunos momentos de uso efetivo da língua materna" (PARISOTTO, 2015, p. 27936).

Nesse interim, o Orientador Pedagógico ${ }^{1}$ (OP) "[...] deve ser o "especialista" nas diversas didáticas (técnicas e métodos) de ensino e o parceiro mais experiente que o corpo docente da escola poderá contar" (SANTOS, 2012, p. 53).

Segundo Silva e Rinaldi (2017) quando o OP presta assistência ao professor e promove a reflexão sobre a prática pedagógica docente e dificuldades que ele encontra para desenvolver seu trabalho, ele "[...] estará favorecendo a tomada de consciência do professor sobre sua atuação e o conhecimento sobre o contexto escolar em que ele atua" (SILVA; RINALDI, 2017, p. 4). Pois, uma das atribuições do OP é:

Prestar assistência pedagógico-didática direta aos professores, acompanhar e supervisionar suas atividades tais como: desenvolvimento dos planos de ensino, adequação de conteúdos, desenvolvimento de competências metodológicas, práticas avaliativas, gestão da classe, orientação da aprendizagem, diagnósticos de dificuldades etc. (LIBÂNEO, 2013, p. 180).

Nesse sentido, no presente estudo, buscaremos responder à seguinte questão: quais são as principais dificuldades que os professores das escolas do município de Presidente Prudente enfrentam para o ensino de língua materna, a partir da ótica do OP?

Desta forma, este trabalho tem como objetivo apresentar as principais dificuldades que os professores das escolas do município de Presidente Prudente enfrentam para o ensino de língua materna, na perspectiva do orientador pedagógico.

\section{METODOLOGIA}

O presente artigo apresenta alguns dos resultados de uma investigação desenvolvida no âmbito da iniciação científica (RINALDI; SILVA, 2016) e que derivou de uma pesquisa maior (PARISOTTO, 2014 ${ }^{2}$ ) que teve sua origem no grupo de pesquisa "Formação de Professores e Práticas de Ensino na Educação Básica e Superior" (FPPEEBS/UNESP) e se caracterizou como uma pesquisa qualitativa. Segundo Minayo (2001, p. 21-22), essa abordagem de pesquisa "[...] trabalha com o universo de significados, motivos, aspirações, crenças, valores e atitudes, o que corresponde a um espaço mais profundo das relações, dos processos e dos fenômenos que não podem ser reduzidos à operacionalização de variáveis".

\footnotetext{
${ }^{1}$ No município de Presidente Prudente o Coordenador Pedagógico é chamado de Orientador Pedagógico.

${ }^{2}$ A pesquisa foi financiada pelo CNPQ (Proc. 472024/2014) e por se tratar de uma investigação que envolve seres humanos, obteve-se autorização do Comitê de Ética em Pesquisa com Seres Humanos (Prot. CAAE 40192114.0.0000.5402). 
O principal objetivo do estudo foi compreender como se configura ensino da língua materna na ótica do orientador pedagógico. Participaram do estudo 21 OPs em exercício em 21 escolas do município. O instrumento que utilizamos para coletar os dados empíricos foi o questionário, que foi organizado de modo a obtermos diversas informações sobre o perfil dos participantes e algumas de suas concepções sobre o tema investigado. Nesta produção, focaremos a análise no perfil dos OPs e somente em uma questão abordada no questionário: quais são as principais dificuldades que os professores da escola enfrentam para o ensino de língua materna. Os resultados foram tratados a partir de uma perspectiva descritivo-analítica.

\section{RESULTADOS}

Os resultados nos permitiram observar, quanto ao perfil dos participantes da pesquisa, que aproximadamente $90 \%$ dos Orientadores Pedagógicos têm até 49 anos de idade, como se pode verificar no Gráfico 1 . Nota-se que $33,4 \%$ estão na faixa etária entre 30 e 39 anos, 57,1\% entre 40 e 49 anos e apenas 9,5\% com mais de 60 anos de idade.

Gráfico 1. Distribuição dos OPs por idade.

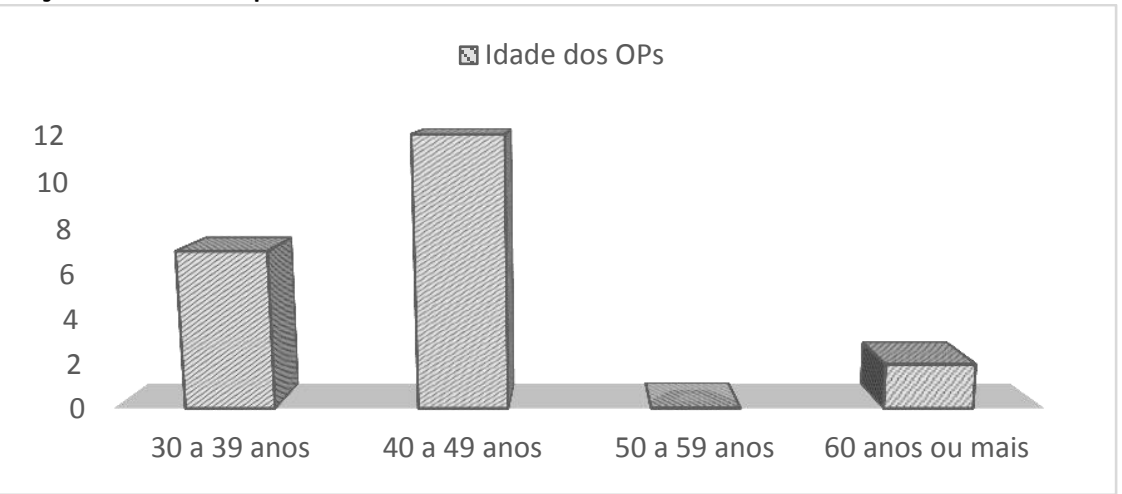

Fonte: Dados organizados pela autora a partir das informações apresentadas no questionário.

Observamos ainda, que todos os participantes cursaram a Licenciatura em Pedagogia, dos quais $47,6 \%$ em instituições públicas de ensino superior e 52,4 em instituições privadas. Do total dos 21 participantes, 4 licenciaram-se em Pedagogia como segundo curso de graduação, todos realizados em instituições privadas de ensino superior. Quanto ao investimento na formação, após a formação inicial $4,7 \%$ dos participantes não apresentou a informação no questionário, 4,7\% concluiu o mestrado e os demais todos concluíram um ou mais cursos de especialização em diversas áreas do conhecimento (ensino de gestão escolar ou Educação Especial).

Foi ainda, dentre os dados analisados quanto ao perfil profissional, observado o tempo de experiência dos OPs no magistério e o tempo de experiência na atual função. Pois, a acreditamos que a docência é uma das condições fundamentais para que o profissional possa assumir a função e desempenhar bem o seu papel. 
Gráfico 2. Distribuição dos OPs por tempo de experiência no magistério e na atual função

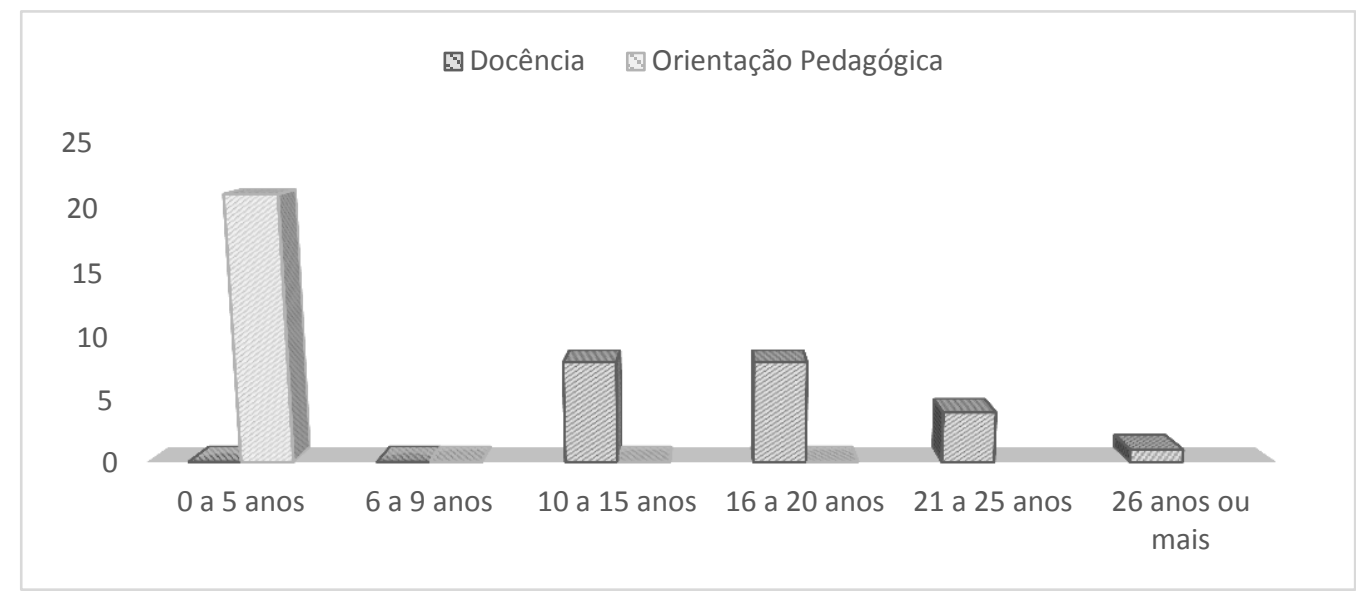

Fonte: Dados organizados pela autora a partir das informações apresentadas no questionário.

Esses achados expostos no Gráfico 2 permitem afirmar que os OPs em exercício nas escolas que participaram da pesquisa têm larga experiência como docentes antes de assumir a nova função na orientação pedagógica. No entanto, todos eles ainda podem ser considerados novatos na função, especialmente porque aproximadamente 62\% iniciavam na função no ano de 2015 quando os dados foram coletados, 19\% tinham entre 1 e 2 anos e 19\% entre 3 e 4 anos.

Quando questionados sobre quais são as principais dificuldades que os professores da escola enfrentam para o ensino de língua materna, diversos apontamentos foram apresentados, tais como: falta de apoio da família, dificuldade de aprendizagem, ortografia, aspectos gramaticais, metodologia, salas numerosas, defasagem no processo de aquisição da escrita, alunos que chagam sem o pré-requisito ao ano a ser cursado, livros inadequados, falta de formação com relação ao tema, dificuldade de planejamento, defasagem de aprendizagem, produção de texto, alunos que não se alfabetizaram na idade certa etc. Vejamos algumas respostas dos orientadores pedagógicos:

Como ensinar para as crianças que possuem dificuldades bastante acentuadas ou atraso no seu desenvolvimento. Como ensinar as crianças que possuem dificuldades no seu comportamento e relacionamento com os demais. OP13

Dificuldades em trabalhar com as defasagens, dificuldades de aprendizagem, disciplina e distúrbios de aprendizagem. OP5

Falta de valores; Indisciplina; Crianças que tiveram danos sérios na gestação. OP7

Crianças com dificuldades de aprendizagem, livros inadequados e salas numerosas. OP12

O desinteresse dos alunos, falta de apoio das famílias, formação mais voltada a estes temas. OP11

Falta de maior participação dos pais na vida escolar dos filhos. Dificuldade de diagnóstico de alguns alunos que apresentam bloqueios na aprendizagem e precisam de investigação. OP14 
Falta de participação dos pais no acompanhamento escolar do filho; Falta de interesse por parte do aluno; Indisciplina. OP17

Percebo, hoje, que muitos professores têm enfrentado problemas por motivos de insegurança, falta de experiência em lidar com séries iniciais, não conhecem o método sociolinguístico, enfrentam dificuldades em lidar com número grande de crianças em sala de aula, baseiam-se muito no uso do livro didático. OP18

Salas numerosas, dificultando um atendimento mais individualizado Alunos que chegam sem os pré-requisitos para o ano em curso. OP19

Atender as necessidades dos alunos que encontram-se em defasagem no processo de aquisição da escrita, pois desejam que todos alcancem o conhecimento da mesma forma e ao mesmo tempo. OP20

O apoio familiar na continuidade do trabalho desenvolvido em sala. Situações que saem do alcance pedagógico, mas que interferem na aprendizagem dos alunos. OP21

\section{DISCUSSÃO}

Do total de 21 participantes, apenas um era do gênero masculino. Isso mostra que, no município de Presidente Prudente, a função de orientador pedagógico é exercida majoritariamente por mulheres. Todos estão em início de carreira com relação à função de OP, mas trazem consigo muitas bagagens e experiências como professores, pois a média de tempo de experiência no campo de magistério é de 17 anos (vide Gráfico 2). Aqui, consideramos iniciantes, como cita Rinaldi (2009), os profissionais que estão exercendo a função por menos de cinco anos. Podemos dizer ainda, que a idade média dos OPs é de 42 anos de idade (vide Gráfico 1) e o menos experiente com relação à função, a exerce há apenas 3 meses, enquanto o mais experiente há 4 anos.

Uma vez que apreendidas características sobre o perfil dos OPs das escolas participantes, passamos a discorrer sobre dificuldade enfrentada pelos professores para o ensino da língua materna, a partir da ótica dos OPs.

Najle e Fiamenghi Júnior (2007, p. 99) destacam que os professores têm enfrentado muitas dificuldades em seu ambiente de trabalho, "[...] pois os alunos não se sentem motivados para aprender, alguns querem apenas conversar com os colegas, outros escutam música, além de apresentar comportamentos agressivos e, muitas vezes, violentos em relação aos professores". Toda essa situação faz com que os docentes se sintam angustiados e alguns até perdem o controle, pois ficam sem saber o que fazer. "Assim os próprios professores desestimulam-se para ensinar, ficam sem desejo para trabalhar e acabam por perder o interesse para com a aprendizagem do aluno" (NAJLE; FIAMENGHI JÚNIOR, 2007, p. 99).

Abordaremos a priori, as falas dos OP5, OP7, OP12 e OP13, que trazem consigo dificuldades como: ensinar as crianças que possuem dificuldades no seu comportamento e relacionamento com os demais, trabalhar com as defasagens, dificuldades de aprendizagem, atraso no seu desenvolvimento e indisciplina. De acordo com Rufino e Souza (2012, p. 45),

Para que haja um bom desempenho no aprendizado do aluno, é necessário que desde o seu nascimento ele tenha recebido valores importantes que mais tarde trará influências positivas, como autoestima, autoconhecimento, respeito, amor, carinho e outros que interferem no 
desenvolvimento do aluno; caso contrário trará dificuldades na aprendizagem. Dentro do processo de aprendizagem os fatores intelectuais, psicomotores, físicos e sociais interferem diretamente, sendo que o fator emocional também é considerado como sendo o responsável por grande parte da formação na educação.

As autoras ressaltam ainda que as crianças que apresentam baixo desempenho escolar e que são classificadas como incompetentes, quase sempre se sentem envergonhadas e são portadoras de baixa estima, e se distanciam do aprendizado "[...] o que geralmente pode vir a acarretar num problema emocional mais grave, após um período vivido dentro desta situação, o que podemos dizer que é um, comportamento interno de sentimentos" (RUFINO; SOUZA, 2012, p. 47-48).

Os alunos mais agressivos, com sentimentos de ira e que também se afastam de seus deveres escolares caracterizam um problema emocional externo. Demonstra também sentimento como frustrações, ou inferioridade devido o fracasso escolar e expondo assim um problema comportamental com explosões emocionais.

Outra dificuldade que também foi bastante apontada pelos OPs, especificamente nas respostas dos OP11, OP14, OP17, OP21, diz respeito à participação e apoio da família na continuidade do trabalho realizado em sala de aula.

A esse respeito, Sousa $(2012$, p. 5) enfatiza que a escola e a família são "[...] parceiras fundamentais no desenvolvimento de ações que favoreceram o sucesso escolar e social das crianças, formando uma equipe". Sendo assim, é primordial que uma e outra, partilhem das mesmas ideias e parâmetros, "[...] bem como a mesma direção em relação aos objetivos que desejam atingir. A educação perpassa tanto o ambiente escolar quanto o familiar. A interação entre ambos é muito importante para o sucesso do processo ensino- aprendizagem" (SOUSA, 2012, p.5). A autora completa ainda que essa parceria entre família e escola, é o principal suporte "[...] com que a criança pode contar para enfrentar desafios, visto que, integradas e atentas podem detectar dificuldades de aprendizagem que ela possa apresentar, podendo contribuir de maneira eficiente em benefício da mesma" (SOUSA, 2012, p. 6).

Para finalizar, destacamos a questão de ensinar um número grande de alunos - salas numerosas - que aparece nas falas dos OP12, OP18 e OP19. Pode-se dizer que essa é uma atividade que atinge grande parte dos professores no Brasil. Uma vez que, sabemos que cada criança aprende de uma forma diferente e que o professor deve ser criativo para proporcionar situações onde seus alunos construam seu conhecimento próprio. Contudo, esse trabalho torna-se ainda mais difícil quando em sua sala de aula há um número extrapolado de crianças. Portanto, concluímos por meio da pesquisa realizada que salas numerosas dificultam de forma significativa o processo de ensino-aprendizagem e, consequentemente, provoca a indisciplina dos alunos.

\section{CONCLUSÃO}

A literatura e as indicações dos OPs, mostraram que o profissional docente enfrenta diversas dificuldades para ensinar a Língua Materna aos seus alunos, nas quais percebemos que uma provoca a outra, ou seja, parecem estar interligadas. Envolvem questões relacionadas ao ensino, estratégias didáticas, recursos, mas vão além delas e extrapolam as paredes da sala de aula e os muros da escola.

Concluímos que para que o OP tenha a capacidade de dar assistência ao professor na sala de sala, para que as dificuldades sejam superadas, é preciso que ele tenha uma ampla bagagem de conhecimentos específicos, sobre a língua materna, bem como sobre as mais diversas dificuldades 
que seus parceiros docentes enfrentam. Mas, precisarão construir novos saberes que se referem a ensinar pessoas adultas (os professores) a ensinar. Somente assim, ele poderá contribuir para uma educação de qualidade em seu local de trabalho, de modo a auxiliar os professores na construção de estratégias pedagógicas para que os estudantes avancem em seus níveis de desenvolvimento e na aprendizagem da língua materna.

\section{REFERÊNCIAS}

LIBÂNEO, José Carlos. Organização e Gestão da Escola - Teoria e Prática. 6. ed. São Paulo: Heccus, 2013.

MINAYO, Maria Cecília de Souza (Org.). Pesquisa social: teoria, método e criatividade. Petrópolis: Vozes, 2001.

NAJLE, Carolina Paz Muñoz; FIAMENGHI JÚNIOR, Geraldo Antônio. Relação professores-alunos com dificuldades de aprendizagem e comportamento: história de mudanças. Cadernos de PósGraduação em Distúrbios do Desenvolvimento, São Paulo, v.7, n.1, p.97-111, 2007. Disponível em: $<$ http://www.mackenzie.br/fileadmin/Graduacao/CCBS/Pos-

Graduacao/RELACAO PROFESSORES ALUNOS.pdf> Acesso em: 09 jun. 2017.

RINALDI, Renata Portela. Desenvolvimento Profissional de Formadores em Exercício: contribuições de um programa on-line. 2009. 231f. Tese (Doutorado em Educação) - Universidade Federal de São Carlos - UFSCar, São Carlos.

RINALDI, Renata Portela; SILVA, Lais Agnes da. A escola como espaço de aprendizagem da profissão: uma reflexão acerca das dificuldades para o ensino da língua materna na ótica do coordenador pedagógico. Projeto de pesquisa financiado pelo CNPQ. Presidente Prudente: FCT/UNESP, 2016.

RUFINO, Dorca; SOUZA, Isabela Augusta Andrade. Dificuldades de aprendizagem na escola: o olhar do professor. Revista Eventos Pedagógicos, v.3, n.3, p. 44 - 52, Ago./Dez. 2012. Disponível em: <http://sinop.unemat.br/projetos/revista/index.php/eventos/article/view/957/647> Acesso em: 09 jun. 2017.

SANTOS, Marcos Pereira dos. O trabalho da trindade pedagógica gestora no contexto educacional escolar da atualidade: algumas reflexões. Imagens da Educação, v. 2, n. 2, p. 49-55, 2012.

Disponível em:

<http://www.periodicos.uem.br/ojs/index.php/ImagensEduc/article/viewFile/15910/9347> Acesso em: 15 jun. 2017.

SILVA, Lais Agnes da; RINALDI, Renata Portela. Concepção do orientador pedagógico sobre o ensino da língua materna. In: II Seminário formação docente: intersecção entre universidade e escola - necessidades formativas nas/das licenciaturas, p. 1-15, 2017.

SOUSA, Jacqueline Pereira de. A importância da família no processo de desenvolvimento da aprendizagem da criança. Universidade Estadual Vale do Acaraú, Fortaleza, 2012. Disponível em: <http://www.apeoc.org.br/extra/artigos cientificos/A IMPORTANCIA DA FAMILIA NO PROCESS O DE DESENVOLVIMENTO DA APRENDIZAGEM DA CRIANCA.pdf> Acesso em: 09 jun. 2017. 
PARISOTTO, Ana Luzia Videira. A formação do professor dos anos iniciais do ensino fundamental para superação do fracasso escolar: perfil teórico-metodológico e propostas para o ensino de língua materna. Projeto de pesquisa financiado pelo CNPQ (Proc. 472024/2014). Presidente Prudente: FCT/UNESP, 2014.

PARISOTTO, Ana Luzia Videira. Ensino de Língua Materna: dificuldades apresentadas pelos professores dos anos iniciais da educação fundamental. In: Educere XII Congresso Nacional de Educação, 2015, Curitiba. Anais do Educere XII Congresso Nacional de Educação, 2015. p. 2793527948. 